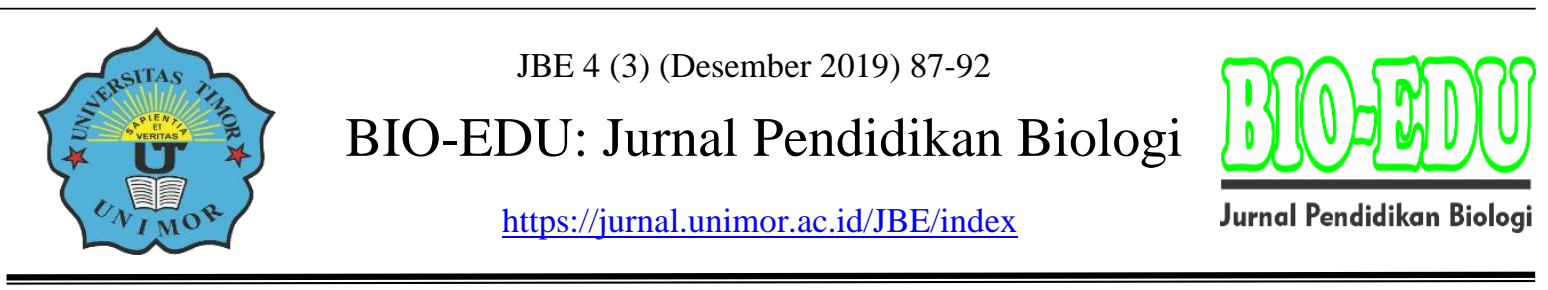

\title{
Indeks Kualitas Air Sungai Noemuti dan Analisis Sensitivitas
}

\author{
Made Santiari \\ Program Studi Pendidikan Biologi, Universitas Timor \\ Email: youthriri@gmail.com
}

DOI: $\underline{\text { https://doi.org/10.32938/jbe.v4i3.415 }}$

\begin{abstract}
Abstrak
Sungai Noemuti merupakan sungai yang berada di Kecamatan Bikomi Selatan dengan panjang $30 \mathrm{~km}$ yang dipantau secara berkala oleh Dinas Lingkungan Hidup Kabupaten Timor Tengah Utara. Informasi hasil pemantauan ini perlu disampaikan sebagai informasi yang sederhana, salah satunya dalam bentuk indeks kualitas air. Penelitian ini bertujuan untuk menghitung nilai indeks kualitas air dan melakukan analisis sensitivitas. Penelitian ini merupakan penelitian dekriptif kuantitatif dengan menggunakan data sekunder berupa hasil pemantauan tahun 2016-2018. Parameter yang diikutsertakan dalam perhitungan indeks kualitas air adalah BOD, COD, TSS, Fecal Coliform dan Total Coliform. Data dianalisis menggunakan rumus indeks pencemaran untuk mendapat nilai indeks kualitas air. Analisis sensitivitas dilakukan dengan empat skenario yaitu menghilangkan parameter a) Fecal Coliform b) Total Coliform c) Fecal Coliform dan Total Coliform d)TSS. Nilai indeks kualitas air sungai Noemuti berkisar antara 0,26-5,28 dengan kategori memenuhi baku mutu hingga cemar sedang. Analisis sensitivitas memberikan gambaran parameter yang berpengaruh pada nilai indeks kualitas air. Skenario keempat merupakan skenario yang menyebabkan berubahnya indeks kualitas air dari kategori cemar sedang menjadi cemar ringan pada data tahun 2017 di titik kedua dan ketiga. Artinya, parameter TSS harus menjadi perhatian untuk meningkatkan kualitas air sungai. Selain itu, hilangnya nilai $\mathrm{Ci} /$ Lij TSS sebagai nilai maksimal menurunkan nilai indeks kualitas air berarti nilai $\mathrm{Ci} / \mathrm{Lij}$ maksimal sangat vital untuk rumus indeks pencemaran. Dari hasil penelitian dapat disimpulkan bahwa sungai Noemuti telah mengalami pencemaran dan parameter TSS adalah parameter yang perlu diperhatikan dalam menyusun rekomendasi pengendalian pencemaran air.
\end{abstract}

Kata kunci : sungai Noemuti, indeks kualitas air, TSS

\begin{abstract}
Noemuti River is a river located in the South Bikomi District with a length of $30 \mathrm{~km}$ that is monitored periodically by the North Central East Regency Environmental Service. Information on the results of this monitoring needs to be conveyed as simple information, one of which is in the form of a water quality index. This study aims to calculate the index value of water quality and conduct a sensitivity analysis. This research is a quantitative descriptive study using secondary data in the form of 2016-2018 monitoring results. The parameters included in the calculation of the water quality index are BOD, COD, TSS, Fecal Coliform, and Total Coliform. Data were analyzed using the pollution index formula to get a water quality index value. Sensitivity analysis was carried out with four scenarios, namely removing parameters a) Fecal Coliform b) Total Coliform c) Fecal Coliform and Total Coliform d) TSS. The Noemuti river water quality index value ranges from 0.26-5.28, with the category good quality to moderately polluted. Sensitivity analysis provides a picture of parameters that influences the water quality index value. The fourth scenario is a scenario that causes a change in the water quality index from the category of moderately polluted to lightly polluted on 2017 data in the second and third points. This means
\end{abstract}

87 Isantiari/JBE 4(3) (Desember 2019 ) 87 - 92 
that TSS parameters must be considered to improve river water quality. Also, the loss of the Ci / Lij TSS value as the maximum value decreases the water quality index value means the maximum $\mathrm{Ci} / \mathrm{Lij}$ value is very vital for the pollution index formula. From the results of the study, it can be concluded that the Noemuti river has been polluted, and TSS is a parameter that needs to be considered in arranging controlling water pollution recommendations.

Keywords: Noemuti river, water quality index, TSS

\section{PENDAHULUAN}

Sungai adalah salah satu ekosistem perairan yang mengalir yang sangat bermanfaat bagi kehidupan manusia (Pasisingi dkk, 2014, 56). Sungai Noemuti merupakan salah satu sungai yang berada di Kecamatan Bikomi Selatan dengan panjang 30 km (BPS 2019, 13). Masyarakat sekitar memanfaatkan sungai ini untuk berbagai aktivitas. Aktivitas masyarakat dapat berpengaruh terhadap kualitas air sungai. Setiap tahun Dinas Lingkungan Hidup Kabupaten Timor Tengah Utara telah melakukan pemantauan kualitas air sungai Noemuti. Informasi hasil pemantauan tersebut harus diinformasikan kepada masyarakat luas.

Ilmuwan dan peneliti telah berupaya untuk menyampaikan kualitas air dengan cara sederhana dan mempunyai dasar ilmiah (Sutadian dkk. 2016, 1). Salah satu cara efektif untuk menyampaikan informasi tren lingkungan khususnya kualitas air sungai dengan menggunakan indeks (Sapkal dan Valunjkar, 2013,120). Indeks kualitas air bertujuan menyajikan sebuah nilai yang dapat mewakili kualitas air (Abbasi dan Abbasi, 2012,4). Indonesia mempunyai dua metode indeks kualitas air yang umum digunakan yaitu metode Indeks Pencemaran dan metode Storet. Kedua metode tersebut memberikan kebebasan dalam menentukan jenis dan jumlah parameter yang digunakan serta penggunaan baku mutu air lokal (Saraswati dkk, 2014,130). Perbedaannya terletak pada kebutuhan data, pada metode Indeks Pencemaran data yang dibutuhkan cukup diambil dari sekali pemantauan, sedangkan metode Storet membutuhkan data dari beberapa hasil pemantauan. Penelitian ini menggunakan data sekunder dari Dinas Lingkungan Hidup Kabupaten Timor Tengah Utara dari tahun 2016-2018. Pemantauan setiap tahun dilaksanakan satu kali kecuali tahun 2016 dilaksanakan dua kali tetapi parameter yang dipantau terbatas. Penelitian ini bertujuan untuk mengetahui indeks kualitas air menggunakan metode Indeks Pencemaran karena keterbatasan data sekunder yang tersedia dan analisis sensitivitas. Diharapkan dengan adanya penelitian ini dapat memberikan infromasi sederhana kepada masyarakat tentang kualitas air sungai menggunakan Indeks Kualitas Air.

\section{METODE}

Penelitian ini merupakan penelitian deskriptif kuantitatif menggunakan data sekunder hasil pemantauan dari Dinas Lingkungan Hidup Kabupaten Timor Tengah Utara. Data sekunder tersebut kemudian dihitung indeks kualitas airnya menggunakan metode Indeks Pencemaran. Rumus Indeks Pencemaran tersaji (PIj) di bawah ini:

$$
P I j=\sqrt{\frac{\left(\frac{C i}{L i j}\right)_{M}^{2}+\left(\frac{C i}{L i j}\right)_{R}^{2}}{2}}
$$

88 Santiari/JBE 4(3) (Desember 2019) $87-92$ 
Evaluasi terhadap nilai PI adalah:

a. $0 \leq \mathrm{PIj} \leq 1$ : memenuhi baku mutu

b. $1,0<\mathrm{PIj} \leq 5,0$ : cemar ringan

c. $5,0<\mathrm{PIj} \leq 10$ : cemar sedang

d. $\operatorname{PIj}>10$ : cemar berat

Sumber: Kementerian Lingkungan Hidup, 2003

Parameter yang digunakan untuk menghitung indeks kualitas air adalah BOD, COD, TSS, Fecal Coliform dan Total Coliform. Baku Mutu Air yang digunakan mengacu pada Peraturan Pemerintah Republik Indonesia Nomor 82 Tahun 2001 tentang Pengelolaan Kualitas Air dan Pengendalian Pencemaran Air kelas 2.

Analisis sensitivitas dilakukan dengan empat skenario yaitu menghilangkan parameter a) Fecal Coliform b) Total Coliform c) Fecal Coliform dan Total Coliform d) TSS.

\section{HASIL DAN PEMBAHASAN}

\section{Indeks Kualitas Air}

Indeks Kualitas Air dengan metode Indeks Pencemaran disajikan pada tabel di bawah ini.

\section{Tabel 1. Indeks Kualitas Air Sungai Noemuti}

\begin{tabular}{|l|l|l|l|l|l|l|l|}
\hline \multirow{3}{*}{ No } & \multirow{2}{*}{$\begin{array}{c}\text { Titik } \\
\text { Pantau }\end{array}$} & \multicolumn{6}{|c|}{ Indeks Kualitas Air } \\
\cline { 3 - 8 } & & Tahun 2016 & \multicolumn{2}{|c|}{ Tahun 2017 } & \multicolumn{2}{l|}{ Tahun 2018 } \\
\cline { 3 - 8 } & Nilai & Kategori & Nilai & Kategori & Nilai & Kategori \\
\hline 1 & I & 0,26 & MBM & 1,42 & CR & 4,51 & CR \\
\hline 2 & II & 1,90 & CR & 5,28 & CS & 3,21 & CR \\
\hline 3 & III & 1,75 & CR & 5,21 & CS & 4,41 & CR \\
\hline
\end{tabular}

Catatan: MBM: memenuhi baku mutu, CR: cemar ringan, CS:cemar sedang, CB:cemar berat.

Nilai indeks kualitas air dengan metode indeks pencemaran untuk Sungai Noemuti berkisar antara 0,26-5,28. Nilai tersebut sebagian besar berada pada kategori cemar ringan. Nilai yang termasuk dalam kategori cemar sedang ada dua yaitu nilai pada titik pantau kedua dan ketiga pada tahun 2017. Penyebab nilai indeks kualitas air tergolong cemar sedang dan cemar ringan harus melihat parameter yang berkontribusi terbesar pada nilai indeks. Parameter tersebut dapat menjadi informasi awal sumber bahan pencemar yang menyebabkan pencemaran. Untuk melihat parameter yang menyebabkan perubahan nilai indeks kualitas air dapat menggunakan analisis sensitivitas.

\section{Analisis Sensitivitas}

Analisis sensitivitas digunakan untuk mengetahui pengaruh pengurangan suatu variabel terhadap indeks (Rickwood dan Carr, 2008, 80). Variabel yang dimaksud disini adalah parameter. Skenario untuk analisis sensitivitas pada analisis ini adalah:

\section{Tanpa parameter Fecal Coliform}

Indeks kualitas air ketika parameter Fecal Coliform dihilangkan dapat dilihat pada tabel di bawah ini. 
Tabel 2. Indeks Kualitas Air Tanpa Fecal Coliform

\begin{tabular}{|c|c|c|c|c|c|c|c|}
\hline \multirow{3}{*}{ No } & \multirow{2}{*}{$\begin{array}{c}\text { Titik } \\
\text { Pantau }\end{array}$} & \multicolumn{4}{|c|}{ Indeks Kualitas Air Tanpa Fecal Coliform } \\
\cline { 3 - 8 } & & \multicolumn{2}{|c|}{ Tahun 2016 } & \multicolumn{2}{c|}{ Tahun 2017 } & \multicolumn{2}{c|}{ Tahun 2018 } \\
\cline { 3 - 8 } & Nilai & Kategori & Nilai & Kategori & Nilai & Kategori \\
\hline 1 & I & 0,25 & MBM & 1,49 & CR & 3,35 & CR \\
\hline 2 & II & 1,91 & CR & 5,29 & CS & 1,86 & CR \\
\hline 3 & III & 1,76 & CR & 5,18 & CS & 1,88 & CR \\
\hline
\end{tabular}

Nilai indeks kualitas air tanpa melibatkan parameter Fecal coliform di setiap titik dan tahun secara umum tidak mengalami perubahan secara signifikan kecuali pada titik kedua dan ketiga pada tahun 2018. Pada titik kedua tahun 2018 terjadi perubahan nilai indeks kualitas air yang dihitung tanpa parameter Fecal Coliform dari 3,21 menjadi 1,86. Namun perubahan nilai ini tidak sejalan dengan perubahan status karena kedua nilai tersebut masih tergolong kategori cemar ringan. Begitu pula dengan titik ketiga pada tahun 2018 terjadi perubahan nilai indeks kualitas air yang cukup signifikan dari 4,41 menjadi 1,88, tetapi kedua nilai tersebut masih tergolong cemar ringan.

\section{Tanpa parameter total coliform}

Nilai indeks kualitas air ketika parameter Total Coliform dihilangkan dapat dilihat pada tabel di bawah ini.

Tabel 3. Indeks Kualitas Air Tanpa Total Coliform

\begin{tabular}{|c|c|c|c|c|c|c|c|}
\hline \multirow{2}{*}{ No } & \multirow{2}{*}{$\begin{array}{c}\text { Titik } \\
\text { Pantau }\end{array}$} & \multicolumn{3}{|c|}{ Indeks Kualitas Air Tanpa Total Coliform } \\
\cline { 3 - 8 } & & \multicolumn{2}{|c|}{ Tahun 2016 } & \multicolumn{2}{c|}{ Tahun 2017 } & \multicolumn{2}{c|}{ Tahun 2018 } \\
\cline { 3 - 8 } & Nilai & Kategori & Nilai & Kategori & Nilai & Kategori \\
\hline 1 & I & 0,26 & MBM & 1,46 & CR & 4,39 & CR \\
\hline 2 & II & 1,92 & CR & 5,29 & CS & 3,17 & CR \\
\hline 3 & III & 1,78 & CR & 5,27 & CS & 4,40 & CR \\
\hline
\end{tabular}

Nilai indeks kualitas air tanpa melibatkan parameter Total coliform di setiap titik dan tahun secara umum tidak mengalami perubahan secara signifikan. Kategori nilai indeks kualitas air masih sama dengan kategori nilai indeks kualitas air dengan melibatkan total coliform.

\section{Tanpa parameter total coliform dan fecal coliform}

Indeks kualitas air ketika parameter Fecal Coliform dan Total Coliform dihilangkan dapat dilihat pada tabel di bawah ini.

Tabel 4. Indeks Kualitas Air Tanpa Total Coliform dan Fecal Coliform

\begin{tabular}{|c|c|c|c|c|c|c|c|}
\hline \multirow{2}{*}{ No } & \multirow{2}{*}{$\begin{array}{c}\text { Titik } \\
\text { Pantau }\end{array}$} & \multicolumn{6}{|c|}{ Indeks Kualitas Air Tanpa Total Coliform dan Fecal } \\
Coliform \\
\cline { 3 - 8 } & & \multicolumn{2}{|c|}{ Tahun 2016 } & \multicolumn{2}{c|}{ Tahun 2017 } & \multicolumn{2}{c|}{ Tahun 2018 } \\
\cline { 3 - 8 } & & Nilai & Kategori & Nilai & Kategori & Nilai & Kategori \\
\hline 1 & I & 0,25 & MBM & 1,56 & CR & 1,41 & CR \\
\hline 2 & II & 1,95 & CR & 5,32 & CS & 1,35 & CR \\
\hline 3 & III & 1,81 & CR & 5,25 & CS & 1,54 & CR \\
\hline
\end{tabular}

90 ISantiari/JBE 4(3) (Desember 2019) 87 -92 
Nilai indeks kualitas air tanpa melibatkan parameter Fecal coliform dan Total Coliform di setiap titik dan tahun secara umum tidak mengalami perubahan secara signifikan. Kategori nilai indeks untuk semua titik dan tahun masih sama dengan semua titik dan tahun dengan pelibatan total coliform dan fecal coliform pada perhitungan.

\section{Tanpa parameter TSS} bawah ini.

Nilai indeks kualitas air ketika parameter TSS dihilangkan dapat dilihat pada tabel di

Tabel 5. Indeks Kualitas Air Tanpa TSS

\begin{tabular}{|c|c|c|c|c|c|c|c|}
\hline \multirow{3}{*}{ No } & \multirow{2}{*}{$\begin{array}{c}\text { Titik } \\
\text { Pantau }\end{array}$} & \multicolumn{6}{|c|}{ Indeks Kualitas Air Tanpa TSS } \\
\cline { 3 - 8 } & & \multicolumn{2}{|c|}{ Tahun 2016 } & \multicolumn{2}{c|}{ Tahun 2017 } & \multicolumn{2}{c|}{ Tahun 2018 } \\
\cline { 3 - 8 } & Nilai & Kategori & Nilai & Kategori & Nilai & Kategori \\
\hline 1 & I & 0,27 & MBM & 1,15 & CR & 4,56 & CR \\
\hline 2 & II & 1,92 & CR & 2,56 & CR & 3,21 & CR \\
\hline 3 & III & 1,77 & CR & 2,67 & CR & 4,42 & CR \\
\hline
\end{tabular}

Nilai indeks kualitas air tanpa melibatkan parameter TSS di setiap titik dan tahun secara umum tidak mengalami perubahan secara signifikan kecuali pada titik kedua dan ketiga pada tahun 2017. Pada titik kedua tahun 2017 terjadi perubahan nilai indeks kualitas air yang dihitung tanpa parameter TSS dari 5,28 menjadi 2,56 dan titik ketiga dari 5,21 menjadi 2,68. Perubahan nilai ini menyebabkan perubahan kategori dari cemar sedang menjadi cemar ringan. Berarti nilai indeks kualitas air di kedua titik tersebut dipengaruhi oleh parameter TSS. Total Suspended Solid (TSS) atau padatan tersuspensi total adalah bahanbahan tersuspensi (diameter $>1 \mu \mathrm{m}$ ) yang tertahan pada saringan pada saringan Millipore dengan diameter $0,45 \mu \mathrm{m}$. TSS terdiri dari atas lumpur dan pasir halus serta jasad-jasad renik, terutama disebabkan oleh kikisan tanah atau erosi tanah yang terbawa ke badan air (Effendi 2003, 64). Parameter inilah yang harus direkomendasikan untuk dikendalikan demi meningkatkan nilai indeks kualitas air.

Jika ditelusuri dari rumus indeks pencemaran, nilai Ci/Lij untuk TSS merupakan nilai maksimum. Besarnya nilai $\mathrm{Ci} / \mathrm{Lij}$ maksimum mempengaruhi besarnya nilai indeks kualitas air dengan metode indeks pencemaran. Berarti $\mathrm{Ci} /$ Lij maksimum sangat mempengaruhi rumus Indeks Pencemaran.

\section{KESIMPULAN DAN SARAN}

\section{Kesimpulan}

1. Nilai indeks kualitas air dengan metode indeks pencemaran untuk Sungai Noemuti berkisar antara 0,26-5,28 dan termasuk dalam kategori memenuhi baku mutu sampai cemar sedang. Secara umum dapat dikatakan sungai Noemuti telah mengalami pencemaran karena sebagian besar nilai indeks berada kategori cemar ringan sampai cemar sedang.

2. Parameter TSS merupakan parameter yang mempengaruhi nilai indeks kualitas air pada tahun 2017 setelah di lakukan analisis sensitivitas. 


\section{Saran}

1. Melakukan analisis sensitivitas dengan menghilangkan parameter lain.

2. Menyusun rekomendasi pengendalian pencemaran air.

\section{DAFTAR RUJUKAN}

Abbasi, Tasneem dan S. A. Abbasi. 2012. Water Quality Indices. Elsevier

BPS. 2019. "Kabupaten Timor Tengah Utara Dalam Angka 2019.” Badan Pusat Statistik Kabupaten Timor Tengah Utara. https://timortengahutarakab.bps.go.id/publication/2019/08/16/9363e7c181090eb4c7 b0f475/kabupaten-timor-tengah-utara-dalam-angka-2019.html.

Effendi, Hefni. 2003. Telaah Kualitas Air Bagi Pengelolaan Sumber Daya dan Lingkungan Perairan. Yogyakarta: Kanisius.

Kementerian Lingkungan Hidup. 2013. Keputusan Menteri Negara Lingkungan Hidup Nomor 115 Tahun 2003 tentang Pedoman Penentuan Status Mutu Air. Jakarta:Kementerian Lingkungan Hidup

Pasisingi, Nuralim, Niken TM Pratiwi, dan Majariana Krisanti. 2014. "Kualitas perairan Sungai Cileungsi bagian hulu berdasarkan kondisi fisik-kimia.” DEPIK Jurnal IlmuIlmu Perairan, Pesisir dan Perikanan 3 (1). https://doi.org/10.13170/depik.3.1.1376.

Rickwood,C.J., dan G.M.Carr.2009.Development and Sensitivity Analysis of a Global Drinking Water Quality Index.Environ Monit Assess.156:73-90. DOI 10.1007/s10661-008-0464-6

Sapkal, R.S. dan S. S. Valunjkar. 2013. Development and Sensitivity Analysis of Water Quality Index for Evaluation of Surface Water For Drinking Purpose.Journal Impact Factor.4(4):119-134

Saraswati, Sri Puji Saraswati, Sunyoto, Bambang Agus Kironoto dan Suwarno Hadisusanto. 2014. Kajian Bentuk dan Sensitivitas Rumus Indeks PI, Storet, CCME untuk Penentuan Status Mutu Perairan Sungai Tropis di Indonesia.Jurnal Manusia dan Lingkungan.21(2).129-142.

Sutadian, Arief Dhany, Nitin Muttil, Abdullah Gokhan Yilmaz, dan B. J. C. Perera. 2016. "Development of River Water Quality Indices-a Review." Environmental Monitoring and Assessment 188 (1): 58. https://doi.org/10.1007/s10661-015-5050-0. 